\title{
Effect of Inbreeding on Preweaning Growth Traits in Egyptian Buffaloes
}

\author{
Ibrahim Atta Abu El-Naser ${ }^{1}$ and Abdullah Ali Ghazy ${ }^{* 2}$ \\ ${ }^{1}$ Department of Animal Production, Faculty of Agriculture, Damietta University, 34517, Damietta, Egypt \\ ${ }^{2}$ Department of Animal Production, Faculty of Agriculture, Suez Canal University, 41522, Ismailia, Egypt
}

Received: $23 / 7 / 2020$

\begin{abstract}
The aims of the current study were to estimate the effect of inbreeding and genetic parameters of birth weight $(\mathrm{BW})$, preweaning daily gain (PDG) and weaning weight (WW) in buffalo calves. Data were collected from weight records of buffalo calves raised at Mahallet Mousa Farms belonging to the Animal Production Research Institute. It included 2015 progeny of 125 sires, through 17 consecutive years. Effect of inbreeding was highly significant for all studied traits. The overall average of inbreeding coefficient was $0.53 \%$ in whole population and $15 \%$ in the inbred animals. The means of BW, PDG and WW in non-inbred group were 37.318, 0.490 and $88.86 \mathrm{Kg}$, respectively. While, the means of the same traits in inbred group were $31.96,0.446$ and $78.82 \mathrm{Kg}$, respectively. Corresponding the inbreeding depression as overall means of levels for above traits were $-0.350,-0.003$ and -0.716 , respectively. Direct heritability $\left(\mathrm{h}^{2}{ }_{\mathrm{a}}\right)$ in inbred animals for BW, PDG and WW were $0.28,0.25$ and 0.19 , respectively. On the other hand, the $\mathrm{h}^{2}{ }_{\mathrm{a}}$ of studied traits in non-inbred animals were $0.32,0.30$ and 0.23 , respectively. The maternal heritability $\left(\mathrm{h}_{\mathrm{m}}^{2}\right)$ for mentioned traits were $0.25,0.26$ and 0.21 within inbred animals and $0.29,0.28$ and 0.22 within non-inbred animals, respectively. Likewise, the genetic correlations $\left(r_{g}\right)$ among studied traits were ranged from $(0.12$ to 0.56$)$ in inbred animals and were ranged from (0.16 to 0.63$)$ in non-bred animals. As well the phenotypic correlation ( $\left.\mathrm{r}_{\mathrm{p}}\right)$ among studied traits were ranged from (0.04 to 0.50$)$ for inbreds and were varied between $(0.04$ and 0.54$)$ for non-inbreds. The inbreeding was pronounced detrimental effects of studied traits in buffalo calves. Therefore, breeding strategies should be develop for reduce the inbreeding effects and inclusion the effects of inbreeding in genetic evaluation programs in Egyptian buffalo calves.
\end{abstract}

Keywords: Preweaning growth traits, inbreeding coefficient, inbreeding depression, Egyptian buffaloes

\section{INTRODUCTION}

Buffalo is one of the most important agricultural animals in Egypt. FAO (2007) reported that Egyptian buffaloes partake to about 5 and $14 \%$ of the world buffalo's milk and meat, successively. The total number of buffaloes in Egypt is about 3.4 million head (FAO, 2017). Egyptian Buffalo is acclimatized animal to the small-holder conditions and is raised under semiextensive production systems. It plays an important economic role in rural areas. Abu El-Naser (2019) showed that it is suitable to select female buffalo calves by birth weight than by weight at other ages. Weights and growth rates in preweaning are an early indicator of the late growth and economic profit (Portolano et al. 2002; Hanford et al. 2006). Inbreeding has harm effects on some economically important traits (Wiggans et al. 1995). Norberg and Sørensen (2007) and Barczak et al. (2009) indicted that the level of inbreeding is mightily impressed by the ratio of males to females, reproduction ability, mating system and population size. Ceyhan et al. (2011) recommended that mating should be made upon a planned system to avoid inbreeding. Increase the number of males that used in breeding strategy and raise the replacement rate would help to decrease the level of inbreeding. It is necessary to control of inbreeding to avoid the negative effects on fertility in further generations (Müller-Unterberg et al. 2017). Mating strategy can resolve inbreeding issues on the farm, at least in the short term, but long-term inbreeding control in a dairy population needs consideration of the relationships among young bulls entering progeny test strategy (Weigeland and Lin 2002). The objectives of this study were to estimate the effect of inbreeding and

*Corresponding author e-mail: ghazy@agr.suez.edu.eg genetic parameters of birth weight, preweaning daily gain and weaning weight in Egyptian buffaloes.

\section{MATERIALS AND METHODS}

\section{Data collection}

Data were collected from weight records of buffalo calves raised at Mahallet Mousa Farms belonging to the Animal Production Research Institute (APRI). It included 2015 progeny of 125 sires, through 17 consecutive years (2000-2016). Studied traits were birth weight $(\mathrm{BW}, \mathrm{kg})$, preweaning daily gain (PDG, $\mathrm{kg}$ ) and weaning weight (WW, kg). Calves after birth, were suckling colostrum during the first three days of their life. They housed individually in calf bed until weaning $\left(15^{\text {th }}\right.$ weeks of age). During suckling period calves were feed natural milk, based on their weight. Moreover, starter was given at the third week of their age up to weaning ( $15^{\text {th }}$ weeks) with berseem hay (Trifolium alexandrinum). Water and mineral mixture were available freely to buffalo calves.

\section{Statistical analysis}

Pedigree structure of the population and inbreeding coefficient were calculated using CFC program (Sargolzaei et al. 2006). The least square means and analysis of variance were estimated for some factors of the studied traits using SAS program (SAS 2002) using the following model:

$$
\begin{gathered}
Y_{i_{j k l m n o}}=\mu+F_{i}+M_{j}+Y_{k}+P_{l}+H_{m}+G_{n} \\
+e_{i j k l m n o}
\end{gathered}
$$

Where:

$\mathrm{Y}_{\mathrm{i}_{\mathrm{jklm} \text { no }}}$ Observation value, $\mu=$ overall mean, $F_{i}=$ fixed effect of $i^{\text {th }}$ inbreeding coefficient, $M_{j}=$ fixed 
effect of $j^{\text {th }}$ month of birth, $Y_{k}=$ fixed effect of $k^{\text {th }}$ year of birth, $\mathrm{P}_{1}=$ fixed effect of $1^{\text {th }}$ parity of dam, $\mathrm{H}_{m}=$ fixed effect of $\mathrm{m}^{\text {th }}$ farm or herd and $\mathrm{G}_{n}=$ fixed effect of $\mathrm{n}^{\text {th }}$ gender and $\mathrm{e}_{\mathrm{ijklmno}}=$ random error term. While estimated inbreeding depression in studied traits via liner regression as recording by (Sokal 1995; Khan et al., 2007).

The (Co) variance components and genetic and phenotypic parameters for traits under study were estimated by MTDFREML suite of programs (Boldman et al. 1995). Apply the following model:

\section{Where:}

$$
\mathrm{Y}=\mathrm{X} \beta+\mathrm{Za}+\mathrm{Mm}+\mathrm{Wpe}+e
$$

$Y=a$ vector of observations, $\beta=$ a vector of fixed effects, $\mathrm{a}=\mathrm{a}$ vector of additive genetic effects, $\mathrm{m}=\mathrm{a}$ vector of maternal genetic effects, $M=$ the incidence matrix relating records to maternal genetic effect, $\mathrm{pe}=\mathrm{a}$ vector of environmental effects contributed by dams to records of their progeny (permanent environmental), W
$=$ the incidence matrix relating records to permanent environmental effects and $\mathrm{e}=\mathrm{a}$ vector of the residual effects. $\mathrm{X}$ and $\mathrm{Z}$ are incidence matrices relating records to fixed and genetic effects, respectively.

\section{RESULTS AND DISCUSSION}

\section{Descriptive statistics}

The statistical analysis of pedigree showed that the overall average of inbreeding coefficient was $0.53 \%$ for the whole population and $15 \%$ for inbred animals. The number of inbred animals were 89 heads from the animals (Table 1). Ceyhan et al. (2011) shown that inbreeding average of all animals overall years was $2.25 \%$ and the rate was $17.7 \%$ in inbred Sakiz sheep lambs. The means of birth weight (BW), preweaning daily gain (PDG) and weaning weight (WW) in all animals were $37.08,0.480$ and $88.42 \mathrm{~kg}$, successively (Table 1).

Table (1): Summary of average inbreeding coefficients and means \pm standard error for birth weight (BW) preweaning daily gain (PDG) and weaning weight (WW) in Egyptian buffalo calves

\begin{tabular}{lccc}
\hline Items & All animals & Non-inbreeds & Inbreeds \\
\hline Traits & Mean & Mean \pm SE & Mean \pm SE \\
BW, kg & $37.08 \pm 0.118$ & $37.318 \pm 0.18$ & $31.96 \pm 0.51$ \\
PDG, kg & $0.480 \pm 0.002$ & $0.490 \pm 0.002$ & $0.446 \pm 0.145$ \\
WW, kg & $88.42 \pm 0.290$ & $88.86 \pm 0.29$ & $78.82 \pm 1.77$ \\
Number of inbreds & & 89 \\
Average inbreeding coefficients in the inbreds & & $15 \%$ \\
Average inbreeding coefficients (all population) & & $0.53 \%$ \\
\hline
\end{tabular}

The mean of BW in all animals was slightly higher than the means that reported by Awad and Afify (2014) and Abu El-Naser (2019) in Egyptian buffaloes (36.30 and $36.56 \mathrm{~kg}$, respectively). However, the mean of WW in all animals was lower than the means that noticed by them 91.31 and $96.95 \mathrm{Kg}$, respectively. The overall mean of PDG in all animals was nearest to the value that estimated by Thevamanoharan et al. (2001) in Swamp buffalo (460.50 g). While, it was higher than estimate that found by Ahmad et al. (2002) in Nili Ravi buffalo $(0.335, \mathrm{~kg})$. The present results were not comparable to outcomes that observed by Khan et al. (2007) in Beetal goats. They found the means of BW, PDG and WW were better in inbreds in comparison with non inbreds. The inbred calves were appeared to ultimately reduce in proportion to 5.358, 0.04 and $10.04, \mathrm{~kg}$ for BW, PDG and WW, respectively (Table $1)$. The current results agree with outcomes of Ceyhan et al. (2011) that presented the effects of inbreeding on birth weight in Sak1z sheep. The effects of inbreeding, year of birth, parity of dam, herd and gender were highly significant $(\mathrm{P}<0.01)$ on all studied traits, except the effect of parity of dam on PDG was not significant (Table 2). While the effect of month of calving was not significant on all traits. The current estimates were compatible with results that found by $\mathrm{Abu}$ El-Naser (2019).

Table (2): Significance levels of some factors affecting on studied traits

\begin{tabular}{|c|c|c|c|c|c|c|}
\hline \multirow{2}{*}{ Traits } & \multicolumn{6}{|c|}{ F- Value and significance } \\
\hline & $\mathbf{F}$ & MO & $\mathbf{Y R}$ & $\mathbf{H}$ & $\mathbf{P}$ & $\mathbf{G}$ \\
\hline BW & $100.95 * *$ & $0.64^{\mathrm{ns}}$ & $7.0 * *$ & $9.71 * *$ & $20.17 * *$ & $22.92 * *$ \\
\hline PDG & $34.77 * *$ & $0.63^{\mathrm{ns}}$ & $17.67 * *$ & $34.51 * *$ & $1.35^{\mathrm{ns}}$ & $38.75 * *$ \\
\hline WW & $74.27 * *$ & $0.47^{\mathrm{ns}}$ & $16.17 * *$ & $12.79 * *$ & $3.47 * *$ & $44.49 * *$ \\
\hline
\end{tabular}


The same results were found by Thevamanoharan et al. (2001) in Swamp buffaloes for effects year of calving and parity of dam on the same traits. Also, the results of the present study agree with Ahmad et al. (2002) for the estimates of the effect of season of birth and parity on birth weight in Nili Ravi buffalo.

\section{Inbreeding coefficient Levels}

The pedigree analysis reflected that 4 animals out of 89 animals (inbreds) had deficient inbreeding coefficient (up to 0.05 ) with a mean value $4.5 \%$. There
31 animals out of 89 animals (inbreds) had low inbreeding coefficient $(0.06$ to 0.10$)$ with mean values $34.83 \%$. Following with animal had medium inbreeding coefficient $(0.11$ to 0.20$)$. The remaining calves (13.48\%) had high inbreeding coefficient ( 0.21 to 0.25$)$ are given in Table 3. The current results revealed that decline for BW, PDG and WW were ranged from -4.84 to $-7.33,-0.03$ to -0.08 and -7.17 to -11.75 , respectively as a result increased inbreeding coefficient levels.

Table (3): Impact of inbreeding coefficients distributions on BW, PDG and WW of buffalo calves

\begin{tabular}{lcccc}
\hline & & \multicolumn{3}{c}{ Traits } \\
\cline { 3 - 5 } $\begin{array}{l}\text { Inbreeding } \\
\text { categories }\end{array}$ & $\mathbf{N}$ & $\mathbf{B W}$ & PDG & WW \\
\cline { 3 - 5 } & & Mean \pm SE & Mean \pm SE & Mean \pm SE \\
\hline Up to 0.05 & 4 & $32.21 \pm 2.54$ & $0.46 \pm 0.08$ & $81.25 \pm 8.25$ \\
$0.06-0.10$ & 31 & $32.00 \pm 0.99$ & $0.44 \pm 0.023$ & $79.67 \pm 3.25$ \\
$0.11-0.20$ & 42 & $31.21 \pm 0.70$ & $0.43 \pm 0.02$ & $78.36 \pm 2.5$ \\
$0.21-0.25$ & 12 & $29.75 \pm 0.68$ & $0.41 \pm 0.08$ & $76.67 \pm 4.89$ \\
\hline
\end{tabular}

Inbreeding depression had perceived for all inbreeding classes and the estimated effects were highly significant $(\mathrm{P} \leq 0.01)$ for all studied traits (Table 4). Regarding, change of inbreeding coefficient $1 \%$ was deleterious for $\mathrm{BW}, \mathrm{PDG}$ and $\mathrm{WW}$ and were ranged from 0.213 to $1.705,0.003$ to 0.031 and 0.490 to 2.407 $\mathrm{kg}$, respectively with different classes of inbreeding coefficient in buffalo calves. El-Arian et al. (2008) reflected that the losses refer to inbreeding, it can be reduced by careful attention to constraint of the mating and accuracy at selection programs for mating using computer.

Table (4): Inbreeding coefficient depression for a change of $1 \%$ in inbreds as liner regression coefficient and standard error in whole population of buffalo calves

\begin{tabular}{|c|c|c|c|}
\hline \multirow{3}{*}{ Classes } & \multicolumn{3}{|c|}{ Traits } \\
\hline & $\mathbf{B W}$ & PDG & $\mathbf{W W}$ \\
\hline & $\mathbf{B} \pm \mathbf{S E}$ & $\mathbf{B} \pm \mathbf{S E}$ & $\mathbf{B} \pm \mathbf{S E}$ \\
\hline Up to 0.05 & $-1.705 \pm 0.639 * *$ & $-0.031 \pm 0.015 * *$ & $-2.407 \pm 0.833 * *$ \\
\hline 0.06-0.10 & $-0.872 \pm 0.150 * *$ & $-0.017 \pm 0.006^{* *}$ & $-1.414 \pm 0.370 * *$ \\
\hline $0.11-0.20$ & $-0.408 \pm 0.065 * *$ & $-0.004 \pm 0.001 * *$ & $-0.847 \pm 0.159 * *$ \\
\hline $0.21-0.25$ & $-0.213 \pm 0.060 * *$ & $-0.003 \pm 0.001 * *$ & $-0.490 \pm 0.147 * *$ \\
\hline Overall mean & $-0.350 \pm 0.043 * *$ & $-0.003 \pm 0.001 * *$ & $-.716 \pm 0.0 .106^{* *}$ \\
\hline
\end{tabular}

Khan et al. (2007) noticed that the inbreeding depression were $0.0004 \mathrm{~kg}, 0.0028 \mathrm{~kg}$, and 0.202 gram for BW, WW and PDG, respectively in all population of Bettal goats. Yavarifard et al. (2014) denoted that increase in inbreeding coefficient $1 \%$, bring about decreased BW and WW by 6.34 and $14.68 \mathrm{~g}$ in Mehraban sheep. It can be appearing from these results that the direct effects of inbreed in the different studied traits, if not controlled them, this will lead to reduced performance for growth traits in buffalo calves in future. Depression of inbreeding is attributable to increased ho mozygosity of individuals. Increased homozygosis brings about lowers thess by increase of the frequency of homozygous recessive unfavorable, and increased homozygosity for alleles at loci (Charlesworth and Willis 2009). Falconer and Mackay (1996) noticed that increasing in inbreeding leads to decrease of genetic variation by decreasing heterozygosity. Doekes et al. (2019) reflected that inbreeding depression was seen in yield traits. For yield traits and based on pedigree, they found that inbreeding through recent generations was more detrimental than inbreeding during distant generations.

\section{Genetic parameters}

Direct heritability $\left(\mathrm{h}_{\mathrm{a}}{ }_{\mathrm{a}}\right)$ of BW, PDG and WW was $0.28,0.25$ and 0.19 , respectively in inbreds and were $0.32,0.30$ and 0.23 , respectively in non-bred animals. 
Table (5): Estimation of direct and maternal heritability for studied traits in non-inbreds and inbreds of Egyptian buffalo calves

\begin{tabular}{|c|c|c|c|c|c|c|}
\hline \multirow{3}{*}{ Estimate } & \multicolumn{6}{|c|}{ Traits } \\
\hline & \multicolumn{3}{|c|}{ Inbreds } & \multicolumn{3}{|c|}{ Non-inbreds } \\
\hline & BW & PDG & WW & BW & PDG & WW \\
\hline$h^{2} a$ & 0.28 & 0.25 & 0.19 & 0.32 & 0.30 & 0.23 \\
\hline$h^{2} m$ & 0.25 & 0.26 & 0.21 & 0.29 & 0.28 & 0.22 \\
\hline $\mathbf{r}_{\mathrm{am}}$ & -0.31 & -0.31 & -0.08 & -0.5 & -0.56 & -0.05 \\
\hline$c^{2}$ & 0.29 & 0.27 & 0.33 & 0.29 & 0.30 & 0.28 \\
\hline$e^{2}$ & 0.18 & 0.22 & 0.27 & 0.10 & 0.12 & 0.27 \\
\hline
\end{tabular}

$\mathrm{h}_{\mathrm{a}}^{2}=$ direct heritability, $\mathrm{h}_{\mathrm{m}}^{2}=$ maternal heritability, $\mathrm{r}_{\mathrm{am}}=$ direct maternal genetic correlation, $\mathrm{c}^{2}=$ fraction phenotypic variance permanent environmental and $\mathrm{e}^{2}=$ fraction phenotypic variance due to residual effects

Corresponding maternal heritability $\left(\mathrm{h}_{\mathrm{m}}^{2}\right)$ for mentioned traits were $0.25,0.26$ and 0.21 of inbreds and $0.29,0.28$ and 0.22 of non-inbreds, respectively (Table 5). The present results showed dissimilar trend of ElAwady et al. (2012) for lifetime performance in Friesian cows. Abu El-Naser (2019) in Egyptian buffaloes illustrated that the $\mathrm{h}_{\mathrm{a}}^{2}$ and $\mathrm{h}^{2} \mathrm{~m}$ of BW were 0.31 and 0.29 , respectively and WW were 0.39 and 0.34 , respectively. As well as Awad and Afify (2014) in Egyptian buffaloes indicated that $\mathrm{h}_{\mathrm{m}}^{2}$ for BW was 0.38 and WW was 0.26. Appreciation direct maternal genetic correlations $\left(\mathrm{r}_{\mathrm{am}}\right)$ in studied traits were negative and contrast between -0.05 to -0.56 in inbreds, Likewise, in non-breds were negative and varied between -0.08 to 0.31 (Table 5). The present results conformed to Abu El-Naser (2019) in Egyptian buffaloes.

The genetic correlations $\left(\mathrm{r}_{\mathrm{g}}\right)$ among different studied growth traits were ranged from 0.12 to 0.56 for inbreds while were ranged from 0.16 to 0.63 for noninbreds (Table 6). Corresponding phenotypic correlations $\left(\mathrm{r}_{\mathrm{p}}\right)$ among above studied traits were varied between (0.04-0.50) within inbreds and it were ranged from $(0.04$ to 0.54$)$ in non-breds (Table 6$)$.

Table (6): Correlations among studied traits in present investigation in Egyptian buffaloes

\begin{tabular}{|c|c|c|c|c|c|c|}
\hline \multirow{2}{*}{ Trait } & \multicolumn{6}{|c|}{ Correlations } \\
\hline & Trait $_{2}$ & $\mathbf{r}_{\mathrm{g}}$ & $\mathbf{r}_{\mathbf{p}}$ & $\mathbf{r}_{\mathrm{e}}$ & $\mathbf{r}_{\text {pe }}$ & $\mathbf{r}_{\mathbf{m}}$ \\
\hline \multicolumn{7}{|c|}{ Inbreds } \\
\hline \multirow{2}{*}{ BW } & P DG & 0.56 & 0.50 & -0.58 & -0.93 & 0.32 \\
\hline & WW & 0.12 & 0.04 & -0.60 & -0.16 & 0.24 \\
\hline PDG & WW & 0.31 & 0.21 & -0.46 & -0.21 & 0.45 \\
\hline \multicolumn{7}{|c|}{ Non-inbreds } \\
\hline \multirow{2}{*}{ BW } & PDG & 0.63 & 0.54 & -0.86 & -0.93 & 0.43 \\
\hline & WW & 0.16 & 0.11 & 0.24 & 0.18 & 0.25 \\
\hline PDG & WW & 0.35 & 0.04 & -0.37 & -0.18 & 0.51 \\
\hline
\end{tabular}

$r_{g}=$ genetic correlation, $r_{p}=$ phenotypic correlation, $r_{e}=$ residual environmental ratio between traits, $r_{p}=$ permanent environmental ratio and $\mathrm{r}_{\mathrm{m}}=$ maternal genetic correlation between traits

These results disagree with El-Awady et al. (2012) in Frisian cow. The estimates of residual ratio were varied between -0.46 and -0.60 in inbreds and varied between -0.86 and 0.24 in non-breds. As well as, the permanent ratio was ranged from -0.21 to -0.93 in inbreds and was ranged from -0.93 to 0.18 in non-breds (Table 6). While the estimates of maternal genetic correlations $\left(\mathrm{r}_{\mathrm{m}}\right)$ among traits were ranged from 0.24 to 0.45 in inbreds and were ranged from 0.25 to 0.51 in non-breds. Which, it is take the same trend of genetic correlations of studied traits (Table 5). Abu El-Naser (2019) noticed that the estimates of $r_{g}, r_{p}$ and $r_{m}$ between $\mathrm{BW}$ and $\mathrm{WW}$ were $0.15,0.45$ and 30 , respectively in Egyptian buffaloes.

\section{CONCLUSION}

The current study indicated that the inbreeding showed a deleterious effect on preweaning growth traits. Therefore, it is necessary to increase monitoring when designing a mating plan in order to control rates of inbreeding in the future, based on complete pedigree information supported via molecular genetics, to achieve a high rate of genetic gain in breeding programs

\section{ACKNOWLEDGMENT}

We extend our sincere thanks and appreciation to all staff of Animal Production Research Institute (APRI) especially staff of Mahallet Mousa station for the data provided to us. 


\section{REFERENCES}

Abu El-Naser I.A.M. (2019). Assessment of genetic relationships between growth traits and milk yield in Egyptian buffaloes. Jurnal Ilmu Ternak dan Veteriner, 24: 143-150. DOI: http://dx.doi.org/10.14334.

Ahmad, M, K. Javed and A. Rehman (2002). Environmental factors affecting some growth traits in Nili-Ravi buffalo calves, Proceedings of the $7^{\text {th }}$ Word Congress Genetics Applied to Livestock production. Montpellier, France.

Awad S. H. and A. A. Afify (2014). Estimation of genetic and phenotypic parameters for growth traits of Egyptian buffaloes using MTDFREML program. J. Agric. Res. Kafr Elsheikh Univ., 40: 742-754.

Barczak, E., A. Wolc, J. Wójtowski, P. Slósarz and T. Szwaczkowski (2009). Inbreeding and inbreeding depression on body weight in sheep. J. Anim. Feed Sci., 18: 42-50.

Boldman, K. L. Kriese, L. Van Vleck, C. Van Tassell and S. Kachman (1995). A manual for use of MTDFREML. A set of programs to obtain estimates of variances and covariances. US Department of Agriculture, Agricultural Research Service, 114.

Ceyhan, A. A. Kaygisiz and T. Sezenler (2011). Effect of inbreeding on preweaning growth traits and survival rate in Sakiz sheep. J. Anim. Plant. Sci, 21: 1-4.

Charlesworth, D. and J. H. Willis (2009). The genetics of inbreeding depression. Nature reviews genetics, 10: 783-796.

Doekes, H. P., R. F. Veerkamp, P. Bijma, G. de Jong, S. J. Hiemstra and J. J. Windig (2019). Inbreeding depression due to recent and ancient inbreeding in Dutch Holstein-Friesian dairy cattle. Genetics Selection Evolution, 51: 54.

El-Arian, M. N., H. G. El-Awady and A. S. Khattab (2008). Effect of inbreeding on dairy traits of Friesian cows in Egypt. J. Agric. Sci. Mansoura Univ., 33: 1811- 1819.

El-Awady, H, A. Salem, A. Halawa and Abo El-Enin (2012). Effect of inbreeding on lifetime performance and genetic parameters estimates of Friesian cows in Egypt. Journal of Agricultural Research, 38: 16-30.

Falconer, D. and T. Mackay (1996). Quantitative genetics: Longman Harrow. Essex, UK/New York.

FAO (2007). Food and Agriculture Organization of the United Nations, FAOSTAT Agriculture Data. http://faostat.fao.org/site/339/default.aspx.

FAO (2017). Food and Agriculture Organization. FAO Statistical Yearbook. Rome (Italy): Food and
Agriculture Organization of the United Nations.

Hanford, K. J., L. D. Van Vleck and G. Snowder (2006). Estimates of genetic parameters and genetic trend for reproduction, weight, and wool characteristics of Polypay sheep. Livestock Science, 102: 72-82.

Khan, M. S., A. Ali and A. U. Hyder (2007). Effect of inbreeding on growth and reproduction traits of Beetal goats.

Müller-Unterberg, M, S. Wallmann and O. Distl (2017). Effects of inbreeding and other systematic effects on fertility of Black Forest Draught horses in Germany. Acta Veterinaria Scandinavica, 59: 1-6.

Norberg, E. and A. C. Sørensen (2007). Inbreeding trend and inbreeding depression in the Danish populations of Texel, Shropshire, and Oxford Down. Journal of Animal Science, 85: 299304.

Portolano, B, M. Todaro, R. Finocchiaro and J. Van Kaam (2002). Estimation of the genetic and phenotypic variance of several growth traits of the Sicilian Girgentana goat. Small ruminant research, 45: 247-253.

Sargolzaei, M. H. Iwaisaki and J. J. Colleau (2006). CFC: a tool for monitoring genetic diversity. Proc. $8^{\text {th }}$ World Congr. Genet. Appl. Livest. Prod., CD-ROM Communication, 13-18.

[SAS] Statistical Analysis System Institute (2002). SAS/STAT User's Guide. (Ver 9). North Carolina (USA): Statistical Analysis System Institute Inc., Cary, NC, USA.

Sokal, R. R., F. J. Rohlf and R. R. Sokal (1995). Biometry : the principles and practice of statistics in biological research. (W.H. Freeman: New York)

Thevamanoharan, K., W. Vandepitte, G. Mohiuddin and C. Chantalakhana (2001). Environmental factors affecting various growth traits of swamp buffalo calves. Pakistan Journal of Agricultural Sciences, 38: 5-10.

Weigeland, K. and S. Lin (2002). Controlling inbreeding by constraining the average relationship between parents of young bulls entering AI progeny test programs. Journal of dairy science, $85: 2376-2383$.

Wiggans, G, P. VanRaden and J. Zuurbier (1995). Calculation and use of inbreeding coefficients for genetic evaluation of United States dairy cattle. Journal of dairy science, 78: 1584-1590.

Yavarifard, R., N. G. Hossein-Zadeh and A. A. Shadparvar (2014). Population genetic structure analysis and effect of inbreeding on body weights at different ages in Iranian Mehraban sheep. Journal of animal science and technology, 56: 34. 


\section{تأثير التربية الداخلية على صفات النمو قبل الفطام في الجاموس المصري

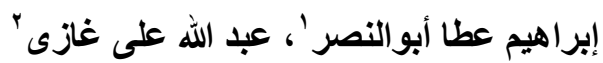

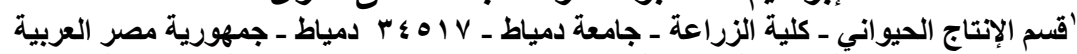

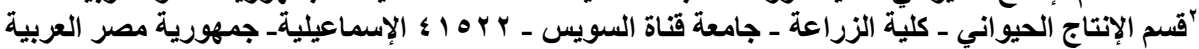

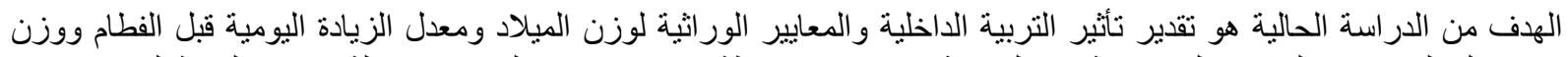



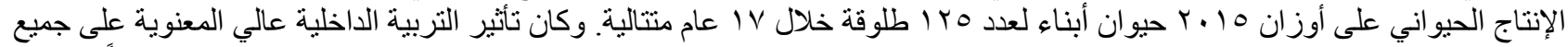

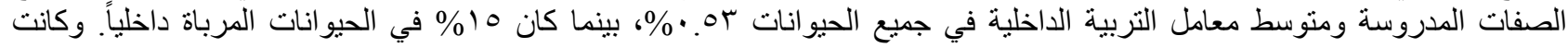

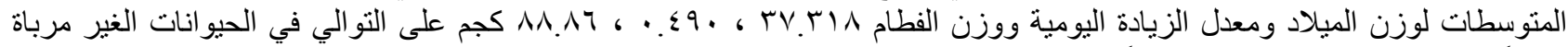

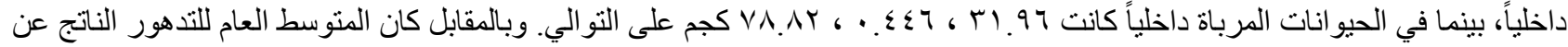

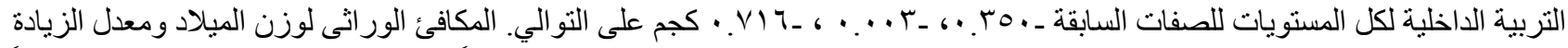

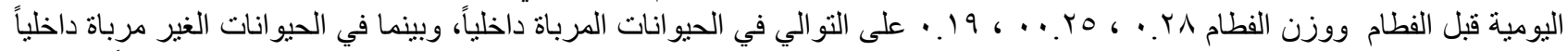



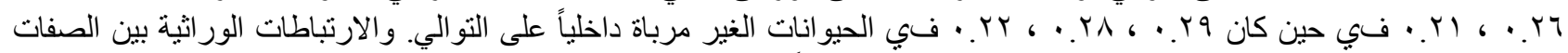

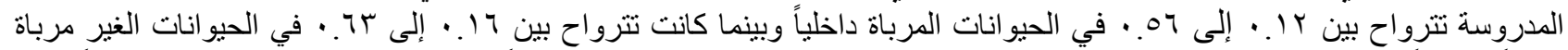

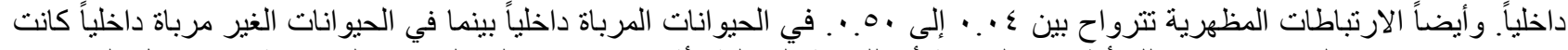



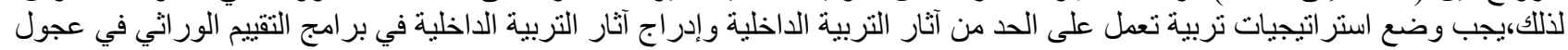

